\title{
ECONOMIC FACTORS IN LIABILITY AND PROPERTY INSURANCE CLAIMS COSTS
}

\author{
NORTON E. MASTERSON
}

The original paper with this title was published in 1968 , following presentation at a Casualty Actuarial Society meeting. This is another up-date of indexes in the economic model-first report of I 976 and a forecast for 1977 . These LPI indexes measure economic factors affecting loss and loss adjustment settlement costs which are incurred after claims have been reported. The indexes measure direct claims costs and not the reinsured excess losses which would be more adversely affected by inflation.

This is a Claims Market Place concept of the loss settlement function of the insurance company. Claims Costs (our economic cost of production) result from purchasing of services under unusual circumstances in controversial, severe, hasty and often emergency situations. Claims settlements can take place in court rooms, lawyers' offices, repair garages and hospitals. The legalistic atmosphere is often one of friction and excessive demand rather than of a normal commercial esprit de corps. The procurement of these claims services requires dealing with high cost furnishers of services: doctors, clinics, hospitals, lawyers, repair garages or body shops, building trades, house furnishings.

\section{U.S. Claims Costs Indexes}

\begin{tabular}{|c|c|c|c|c|c|c|c|}
\hline & \multicolumn{7}{|c|}{$1967=100$} \\
\hline & $197 \mathrm{I}$ & 1972 & 1973 & 1974 & 1975 & 1976 & $1977^{*}$ \\
\hline Auto Bodily Injury & I 39.4 & 147.1 & 157.1 & I 71.6 & 191.9 & $2 \mathrm{I} 4.5$ & 235.8 \\
\hline Auto Property Damage & I 39.3 & 150.9 & 163.3 & 172.7 & I9O.I & 210.3 & 228.2 \\
\hline Auto Physical Damage & I 39.0 & I 52.2 & $\mathrm{I} 64.5$ & 172.3 & I 89.1 & 210.2 & 227.9 \\
\hline Sub-total All Auto & $\overline{139.5}$ & $\overline{149.6}$ & $\overline{160.7}$ & $\overline{I 7 I .1}$ & 190.5 & $2 \mathrm{I} 2 . \mathrm{I}$ & 231.4 \\
\hline Workers' Compensation & $\mathrm{I} 43.8$ & I 55.0 & I 7 I.4 & 189.0 & 218.4 & $244 \cdot 7$ & 272.3 \\
\hline Other Bodily Injury & I 39.9 & $\mathrm{I} 47.7$ & I 57.2 & I 7 I 8 & 192.2 & 214.8 & $235 . I$ \\
\hline Other Property Damage & $\mathrm{I} 33.2$ & I $42 . \mathrm{I}$ & I 53.7 & 161.9 & 177.0 & 197.2 & $2 \mathrm{I} 3.9$ \\
\hline
\end{tabular}

* Forecast 
Glass

Burglary \& Theft

Boiler \& Machinery

Fire

Allied Lines

Homeowners

Commer. Multi, Peril

Inland Marine

Composite
$1967=100$

\begin{tabular}{|c|c|c|c|c|c|c|}
\hline $7 I$ & $97^{2}$ & 1973 & 1974 & 1975 & 1976 & 1977 \\
\hline 06 & 5.2 & I 42.8 & I 49.5 & .2 & 75.6 & 187.7 \\
\hline 7.6 & 9 & & & & & 96 \\
\hline 3. & I 31.9 & & & & & \\
\hline & 146.0 & & & & & \\
\hline & 45.2 & & & & 199.2 & 213 \\
\hline & $\mathrm{r} 44.0$ & 156 & 170.4 & & 199.9 & 217. \\
\hline & 17.0 & 160.8 & 172.6 & & 202.0 & 215 \\
\hline & I 32.1 & I43.I & I 53.4 & I 66.2 & I 79. I & I90.5 \\
\hline & 48. & 160.7 & $\overline{173.8}$ & & 213.4 & 233. \\
\hline
\end{tabular}

Auto and other bodily injury liability and workers' compensation indexes reflect large increases in charges for physicians' fees, hospital daily room rates, wages and salaries, attorney fees and other legal expenses. In addition, for workers' compensation, indemnity loss costs have escalated because of law amendment factors which produce higher benefit levels. Physicians' fees and hospital charges have reflected the higher insurance rates for medical malpractice coverage.

Auto property damage and physical damage indexes continued their sharp increases due to higher costs of replacement parts, body shop labor rates and other charges related to auto crash-damage repairs. Of the total dollar amounts of incurred loss and loss adjustment expenses in 1975 and 1976 , approximately $43 \%$ involved auto bodily injury liability and $57 \%$ involved auto physical damage and property damage (principally other motor vehicles). The towtruck now transports more insurance losses than does the ambulance! One of the disturbing facts of the past decade has been the escalating costs of car-damage repairs compared with auto bodily injuries in spite of trends in personal injury costs due to no-fault, tort liability, medical expenses and attorney fees plus extra costs for assigned risk plans and other substandard risks.

Property coverage indexes for residences, commercial buildings and structures, personal property and commercial property soared to record heights because of very high prices for materials, construction labor, and financing. 


\section{FUTURE WARNings}

"One cannot steer a ship by looking at the wake"

The large increases in all LPI indexes by lines for the five-year period, I97I to I976, were caused by high inflationary prices for the three major components affecting casualty and property insurance in three groups: Medical Care, Car-Damage Repairs and Construction Costs (residential and commercial). Five year forecasts by Data Resources, Inc. (I976 to I98I) for most of the component indexes in those three groups give warnings of continued inflationary costs far exceeding the forecasts for the standard Consumer Price Index in the United States.

There are several political factors which will intensify the normal operation of price economics in our claims-market-place. Most disturbing will be continuing government fiscal deficits feeding inflation (which has always been more severe for underlying claims costs than for the standard Consumer Price Index; national health insurance; government energy policies affecting the use of and cost of motor car operation; and pressures which force more and more of the insurance costs of unfavorable risks onto the favorable underwriting risks with such increased costs allocated on a political rather than on an actuarial basis.

While the emphasis in this discussion is on economic considerations in the analyses of claims costs, the same economic indexing principles and procedures are adaptable to indexing loss elements in pricing, and in indexing claims reserves for financial purposes. 